\title{
The Temporal Association of Sphenoid Sinus Mucosal Thickening on MR Imaging with Pituitary Apoplexy
}

\section{MR Görüntülemesinde Sfenoid Sinüs Mukoza Kalnlaşmasmmn Pitüiter Apopleksiyle Temporal IIlişsisi}

\author{
Basheal AGRAWAL ${ }^{1}$, Kristine DZIURZYNSKI ${ }^{2}$, M. Shariar SALAMAT ${ }^{3}$, Mustafa BASKAYA ${ }^{1}$ \\ ${ }^{1}$ University of Wisconsin, Department of Neurological Surgery, Madison/WI, USA \\ ${ }^{2}$ University of Mississippi, Department of Neurological Surgery, Jackson/MS, USA \\ ${ }^{3}$ University of Wisconsin, Department of Pathology, Madison/WI, USA
}

Correspondence address: Basheal AGRAWAL / E-mail: b.agrawal@neurosurg.wisc.edu

\begin{abstract}
AIM: Pituitary apoplexy is an infrequent but potentially devastating complication in patients with pituitary adenomas. Previous studies have cited an association between MR visualized sphenoid sinus mucosal thickening and apoplexy. However, uncertainties still remain on the significance and temporal association of this finding with pituitary apoplexy. We provide a clinical study that better delineates this temporal association and also provides histopathologic data for sinus thickening compared to control subjects.

MATERIAL and METHODS: We report on two patients who received serial MR scans leading to the diagnosis of pituitary apoplexy. Patient 1 demonstrated new sphenoid sinus mucosal thickening with the onset of apoplexy. Patient 2 had progressive thickening of sphenoid sinus mucosa from presentation to repeat scanning demonstrating apoplexy. Both patients underwent transsphenoidal resection of their pituitary adenomas with pathology demonstrating inflamed sphenoid sinus mucosa.

CONCLUSION: Sphenoid sinus mucosal thickening, as demonstrated on MRI, is temporally associated with pituitary apoplexy, likely as an acute and precedent finding.
\end{abstract}

KEYWORDS: Pituitary apoplexy, Sphenoid sinus, Magnetic resonance imaging

öz

AMAÇ: Pitüiter apopleksi pitüiter adenomları olan hastalarda sık görülmeyen ama çok tehlikeli olabilecek bir komplikasyondur. Önceki çalışmalar MR'de sfenoid sinüste mukoza kalınlaşması görülmesiyle apopleksi arasında bir ilişki belirtmiştir ancak bu bulgunun pitüiter apopleksiyle temporal ilişkisi ve önemi halen şüphelidir. Burada bu temporal ilişkiyi daha iyi gösteren bir klinik çalışma sunuyoruz ve ayrıca kontrol hastalarıyla karşılaştırıldığında sinüs kalınlaşması için histopatolojik veriler sağlıyoruz.

YÖNTEM ve GEREÇLER: Pitüiter apopleksi tanısı koyacak şekilde seri MR taramaları yapılan iki hasta bildiriyoruz. Hasta 1'de apopleksi başlangıcıyla yeni sfenoid sinüs mukoza kalınlaşması görüldü. Hasta 2'de başlangıçtan apopleksinin görüldüğü tekrar taramaya kadar sfenoid sinüs mukozasında progresif kalınlaşma saptandı. Her iki hastada pitüiter adenom için transsfenoidal rezeksiyon yapıldı ve patoloji enflame sfenoid sinüs mukozası gösterdi.

SONUÇ: MRG'de gösterildiği şekilde sfenoid sinüs mukoza kalınlaşması muhtemelen akut ve önceki bir bulgu şeklinde temporal olarak pitüiter apopleksiyle ilişkilidir.

ANAHTAR SÖZCÜKLER: Pitüiter apopleksi, Sfenoid sinüs, Manyetik rezonans görüntüleme

\section{INTRODUCTION}

Pituitary apoplexy is classically defined as acute hemorrhage or infarction of a pituitary adenoma. Apoplexy occurs in $1-2 \%$ of patients with pituitary adenomas and has a clinical syndrome consisting of acute headache, meningismus, visual impairment, opthalmoplegia, and alterations of consciousness. Without treatment, patients can succumb to subarachnoid hemorrhage with increased intracranial pressure and hypopituitarism. The pathophysiologic mechanisms leading to pituitary apoplexy are not well understood, however, the following mechanisms have been proposed: ischemic necrosis of a rapidly growing tumor, intrinsic vascular anomalies within that particular tumor, or compression of the superior hypophyseal artery against the diaphragma sella $(2,4,5)$.

With MRI becoming the standard imaging technique in the diagnosis of pituitary adenomas, two studies have been published describing the association of sphenoid mucosal thickening with apoplexy (1, 3). In 2001 Arita et. al., described 
MRI and histopathological findings of acutely thickened sphenoid mucosa ( $>1 \mathrm{~mm}$ thickening) in 11 consecutive patients presenting with apoplexy (1). Nine of the 11 patients with apoplexy demonstrated thickened sphenoid mucosa on MRI; histopathological findings of four patients with sphenoid sinus mucosa demonstrated a swollen subepithelial layer. In contrast, only fifteen of 100 consecutive patients with nonapoplectic pituitary adenomas demonstrated sphenoid mucosa thickening; moreover, five of these patients were found to have pan-sinusitis.

Liu et al., describe their experience with this population and generated a grading scale based upon clinical presentation: Grade I-presence of headaches and/or endocrine abnormalities only; Grade II-presence of the aforementioned symptoms plus cranial nerve deficits; and Grade III-presence of the foregoing symptoms with altered level of consciousness. In Liu's series, 22 of 28 patients with apoplexy were found to have sphenoid sinus mucosal thickening, with all Grade II and III patients demonstrating thickening. Furthermore, apoplectic patients with thickened sphenoid sinus mucosa were more likely to have higher grades of apoplexy, worsened neurological outcome, and increased rates of hypopituitarism with long-term hormone replacement therapy (3).

In this case report, we seek to add credence to Arita's and Liu's observations, as well as to better delineate the time course of sphenoid sinus mucosa thickening in temporal relation to pituitary apoplexy. Furthermore, unlike the previous studies, we have analyzed the sphenoid sinus mucosa in a semiquantitative manner, and compared them to the sphenoid sinus mucosa obtained from a patient with an electively removed pituitary adenoma and from a patient with lymphocytic hypophysitis. In conjunction with the previously mentioned studies, we suggest that the presence of sphenoid sinus thickening on MR in the pre-apoplectic patient should lead to consideration for early surgery.

\section{PATIENTS and METHODS}

During the senior author's (MKB) experience, two patients with pituitary apoplexy had presented with serial MR imaging prior to their apoplectic event. Each patient presented with the classic symptoms described above. Apoplexy was defined radiographically by hyperintensity on T1-weighted MR imaging and/or as evidenced by gradient echo sequences. The sphenoid sinus mucosa was measured on mid-sagittal T1-weighted MR images. Thickening of the sphenoid sinus mucosa was defined using the convention established by Arita, et al. as greater than $1 \mathrm{~mm}$ of thickening (1). Intraoperative specimens, after transsphenoidal surgery, were sent for histopathology and evaluated by hematoxylin and eosin. Apoplexy was defined histologically by the presence of necrosis or hemorrhage. The sphenoid sinus mucosa was semiquantitatively graded on the presence of edema, judged by tissue pallor, and on the presence of inflammatory infiltrate. A range between zero and four points was assigned to edema and infiltrate, with a total score of eight defining maximal inflammation (Table I). The sphenoid mucosa from a patient who underwent elective transsphenoidal surgery for a pituitary adenoma and the mucosa from another patient with lymphocytic hypophysitis were used for comparison.

\section{Case 1:}

A 46-year-old man presented with spontaneous left vertebral artery dissection and resultant cerebellar hemisphere stroke. He had no focal neurological deficits other than left dysmetria and dysdiadochokinesia. MRI obtained at the time of diagnosis revealed an incidental pituitary adenoma. Endocrine evaluation found that he had decreased libido with a hormonal profile showing decreased testosterone levels and mildly increased prolactin. Prolactin elevation was attributed to stalk effect. There was no other evidence for hormonal dysfunction. He was placed on Coumadin for the vertebral dissection and referred to the neurosurgery service for discussion of surgical management. One month later, a new MRI was obtained with a dedicated pituitary protocol; neither this nor the previous MRI showed any evidence of sinusitis or sphenoid sinus mucosal thickening (Figure 1A, B). Surgery was deferred for six months to allow completion of his course of Coumadin.

During the patient's sixth month of Coumadin therapy (INR=1.8) he presented to the emergency department complaining of acute onset of severe headache and diplopia. Examination demonstrated an awake, alert, and oriented patient but with unilateral third nerve palsy and decreased visual acuity. Non-contrast CT scan and MRI of the brain at this time (four months after last imaging) revealed hemorrhage in the sellar region. This MRI also demonstrated remarkably thickened sphenoid mucosa, not seen on his previous scans (Figure 2A-C). Measured sphenoid mucosal thickening was $3.3 \mathrm{~mm}$. There was no enhancement in any of the other air sinuses, nor did the patient have symptoms of sinusitis, to suggest infection.

The patient was taken emergently to the operating room for decompression of this Hardy IIA tumor through a translabial transsphenoidal approach. There was no defect in the sellar floor causing communication of the sella to the sphenoid sinus. Near total resection of the infiltrating adenoma was achieved with a small remnant in the cavernous sinus. Intraoperatively, the sphenoid sinus mucosa was found to be thickened and inflamed. Pathology revealed focal necrosis and hemorrhage in a nonsecreting pituitary adenoma. The sphenoid mucosa showed 3+ edema and 1+ infiltrate (moderate inflammation). While macrophages were present,

Table I: Semi-Quantitative Grade of Sphenoid Sinus Mucosal Inflammation as Determined by the Combination of Score for Mucosal Edema and Inflammatory Infiltrate

\begin{tabular}{|c|c|}
\hline Total Score & Grade of Mucosal Inflammation \\
\hline $0-2$ & Mild \\
$3-5$ & Moderate \\
$6-8$ & Severe \\
\hline
\end{tabular}



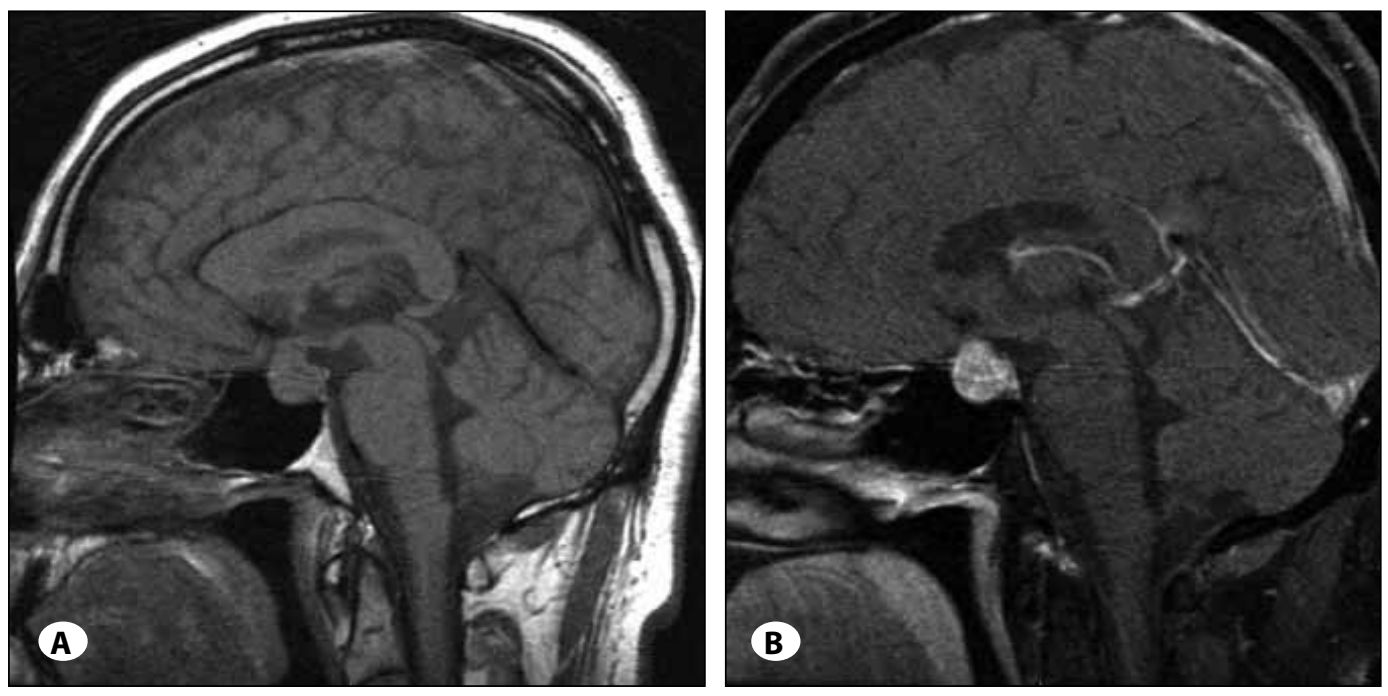

Figure 1: A) Midsagittal, non-enhanced T1-weighted MRI of Patient 1 showing a pituitary macroadenoma without associated sphenoid sinus mucosa thickening.

B) Gadoliniumenhanced mid-sagittal T1-weighted MRI of Patient 1.
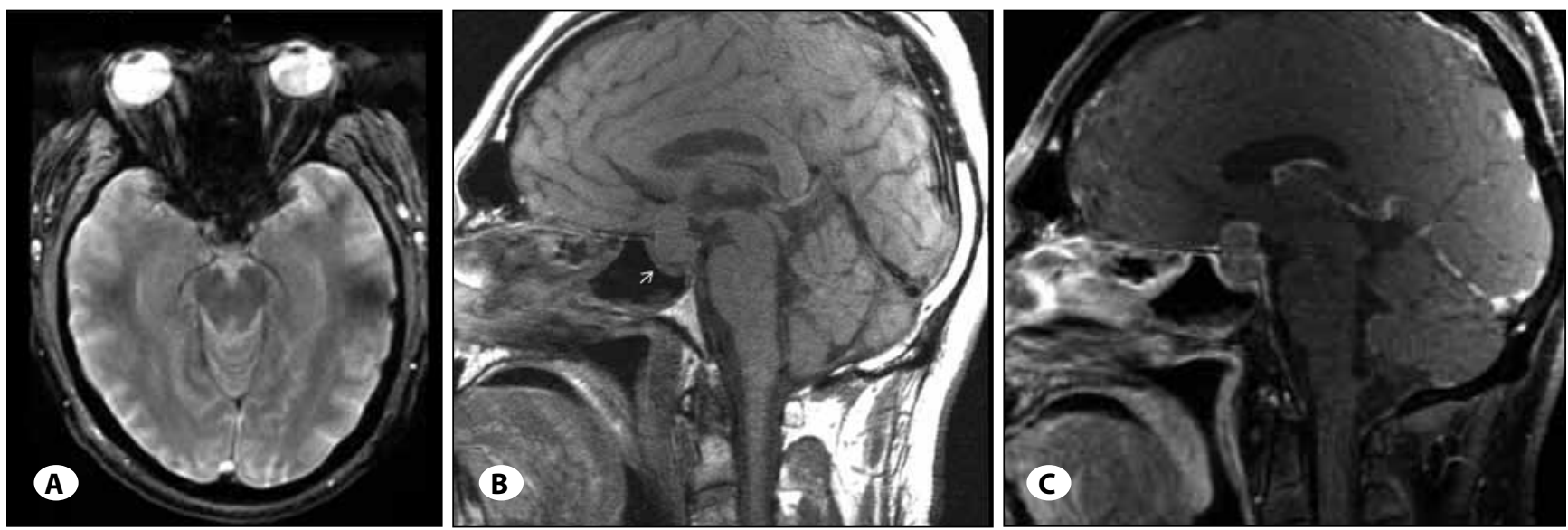

Figure 2: A) T2* axial image through the sella of Patient 1 demonstrating hemorrhage. B) Mid-sagittal, non-enhanced T1-weighted MRI of Patient 1 showing sphenoid sinus mucosa thickening to $3.3 \mathrm{~mm}$ (arrow). C) Gadolinium-enhanced mid-sagittal T1-weighted MRI of Patient 1 demonstrating circumferential sphenoid sinus mucosa thickening.

they did not contain hemosiderin, likely due to the acuity in which the patient was taken to the operating room. The patient made an excellent recovery and his extraocular eye movements and visual acuity returned to normal.

\section{Case 2:}

A 49-year-old man who presented to the emergency room with acute onset of headache, but no visual changes or cranial nerve deficits. He was awake and fully alert. CT and MRI scans demonstrated a sellar mass without evidence of infarct or hemorrhage. There was, however, mildly thickened sphenoid mucosa measuring $1.3 \mathrm{~mm}$ (Figure 3AC). Hormonal profile was normal with the exception of mildly elevated FSH. Three days after admission he underwent a second MRI in preparation for transsphenoidal resection. This MRI demonstrated interval sphenoid mucosal thickening, without thickening of other sinus mucosa, and presence of a small amount of hemorrhage in the pituitary, suggesting pituitary apoplexy (Figure 4A-C). At this time, the sphenoid mucosa measured $4.1 \mathrm{~mm}$. There had been no change in his neurologic examination; he remained without deficit and only complained of headache.

He underwent translabial transsphenoidal resection of a Hardy IIC pituitary adenoma. Again, intraoperatively the sphenoid sinus mucosa appeared inflamed. There was no sellar floor defect. Histology revealed a FSH producing pituitary adenoma with acute necrosis and hemorrhage. Sections of sphenoid mucosa demonstrated thickened mucosa with $2+$ edema and $1+$ chronic inflammatory cell infiltrate (moderate inflammation). Extravasated blood central to the tumor was histologically present, suggesting an apoplectic event. The patient's headache resolved shortly after surgery.

\section{DISCUSSION}

Pituitary apoplexy is a potentially devastating complication occurring in approximately $2-7 \%$ of individuals with pituitary adenomas. With MR imaging becoming more commonly available, the ability to detect pituitary apoplexy has greatly 

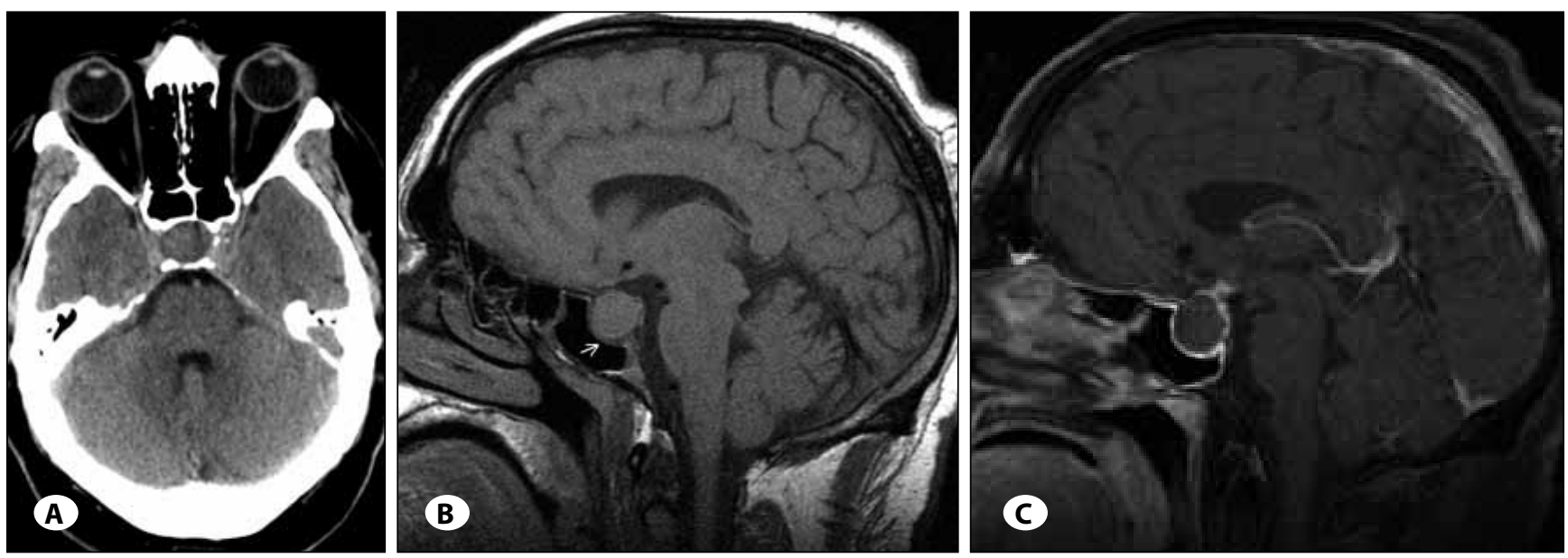

Figure 3: A) Non-contrasted axial CT scan of Patient 2 through the sella without any obvious hemorrhage. B) Mid-sagittal, nonenhanced T1-weighted MRI of Patient 2 showing sphenoid sinus mucosa thickening to $1.3 \mathrm{~mm}$ (arrow). C) Gadolinium-enhanced mid-sagittal T1-weighted MRI of Patient 2.
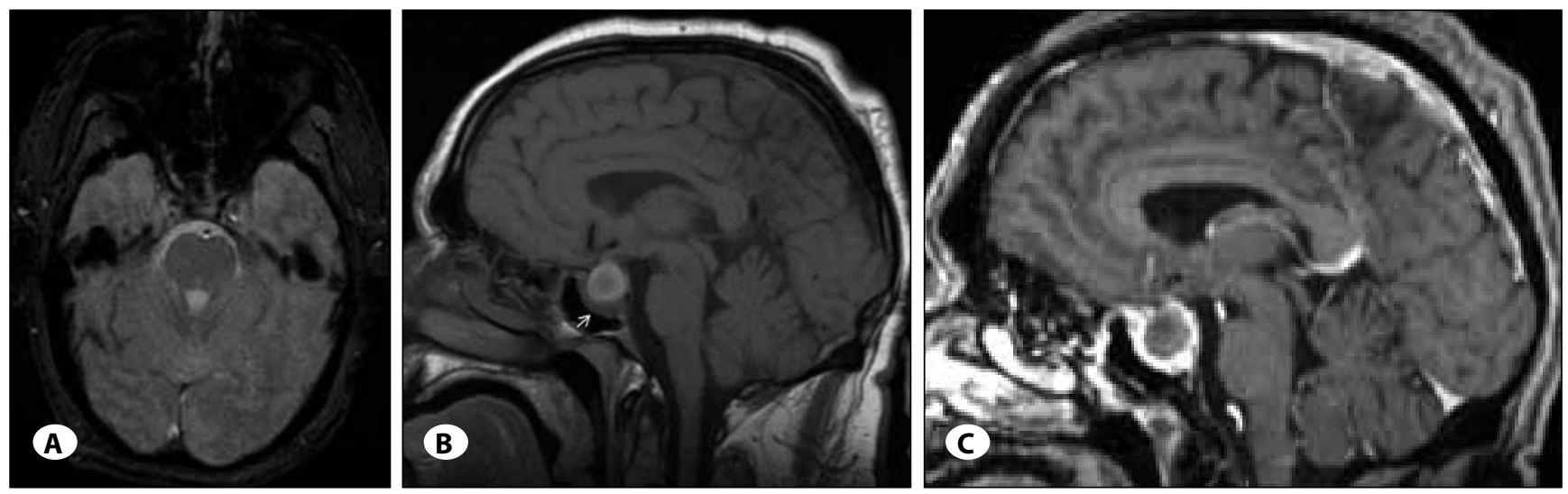

Figure 4: A) T2* axial image through the sella of Patient 2 demonstrating hemorrhage. B) Mid-sagittal, non-enhanced T1-weighted MRI of Patient 2 showing sphenoid sinus mucosa thickening to $4.1 \mathrm{~mm}$. C) Gadolinium-enhanced mid-sagittal T1-weighted MRI of Patient 2 re-demonstrating sphenoid sinus mucosa thickening.

aided in treatment of these patients. With the precision of MR imaging, and in considering previous case reports, our group further investigated the association of sphenoid sinus mucosal thickening on MR imaging with pituitary apoplexy.

Our case report provides support to Arita's and Liu's studies and better delineate the appearance of sphenoid sinus mucosa in pituitary apoplexy. In Arita's study, two patients had pre- and post- apoplectic MRI (1). In one of these patients, the interval time between scans was 15 days, and in the other patient it was 18 months. In Liu's study, there was no mention of preapoplexy MRI (3). With these studies, it is unclear within what time frame sphenoid sinus mucosa thickens in the setting of pituitary apoplexy. It is unknown if thickening represents an acute phenomenon either immediately preceding the apoplectic event or if it is secondary to it.

The experiences with our patients suggest that thickening of the sphenoid mucosa is an acute phenomenon. Both of our patients were known to have pituitary adenomas, without a history of sinus disease, prior to their diagnosis of apoplexy on MR-imaging. In our first patient, serial MRI scans demonstrated normal sphenoid sinus, with thickening occurring only on the apoplectic MR. Two MR scans had been performed on this patient prior to his apoplectic event; neither of these scans demonstrated radiographic abnormality in the sphenoid sinus mucosa. The interval between his apoplexy MR scan and his previous imaging was four months. While it is possible that this patient's sphenoid mucosa thickened in the four months between his scans due to some other disease pathology, it is most likely associated with the apoplexy, especially given his lack of concurrent symptoms. This is further substantiated by the lack of microscopic fibrosis in the sphenoid mucosa. This case reaffirms the relation between the radiographic appearance of the sphenoid sinus mucosa and pituitary apoplexy, as opposed to thickening being a coexisting phenomenon.

In the second patient, the interval between the pre-apoplexy MRI and his MRI scan demonstrating apoplexy was three days. 
This patient presented with the onset of acute headaches. His admission MRI demonstrated no apoplexy, but the sphenoid mucosa was thickened to $1.3 \mathrm{~mm}$. An increase in the mucosal thickness of $2.8 \mathrm{~mm}$ occurred in conjunction with the demonstration of pituitary apoplexy on MR scans, as evidenced by intratumoral hemorrhage. It is plausible that these headaches heralded pituitary apoplexy, suggesting that the radiographic appearance of thickened sphenoid sinus mucosa forewarns of more catastrophic sellar activity (at least on imaging exams) and should prompt early surgery.

After review of the study by Arita, we hypothesized that the sphenoid mucosa from our patients would reveal more edema and infiltrate than control subjects (1). Edema and inflammatory infiltrate were thought to be correlative to radiographic presence of sphenoid sinus thickening. On the contrary, however, there was no resounding difference in the characteristics of the mucosa after examination of sphenoid sinus mucosa from our two patients in contrast to the sphenoid mucosa of patients with other intrasellar processes. The sphenoid mucosa from our patients demonstrated moderate inflammation (Figure 5A, B). Mucosa from a patient with an electively removed pituitary adenoma and that from a patient with lymphocytic hypophysitis, however, also showed similar semi-quantitative inflammation profiles (Figure 6A, B). Mucosa from the electively removed adenoma showed 1+ edema and $2+$ infiltrate (moderate inflammation). Mucosa from a patient with lymphocytic hypophysitis had 2+ edema and $3+$ infiltrate (moderate inflammation). Of note, MR imaging of the control patients did not reveal sphenoid sinus mucosal thickening. This suggests that while sphenoid sinus mucosa radiographically thickens with pituitary apoplexy, it is not a unique characteristic on histology.

The presence of radiographically thickened sphenoid sinus mucosa can be associated with pituitary apoplexy. Our study lends credence to the studies by Arita and Liu and further suggests that thickening of sphenoid mucosa, in the setting of a pituitary adenoma, may be an ominous sign. While our study is a small case series, it should prompt further investigation into the radiographic and pathologic characteristics of pituitary apoplexy.
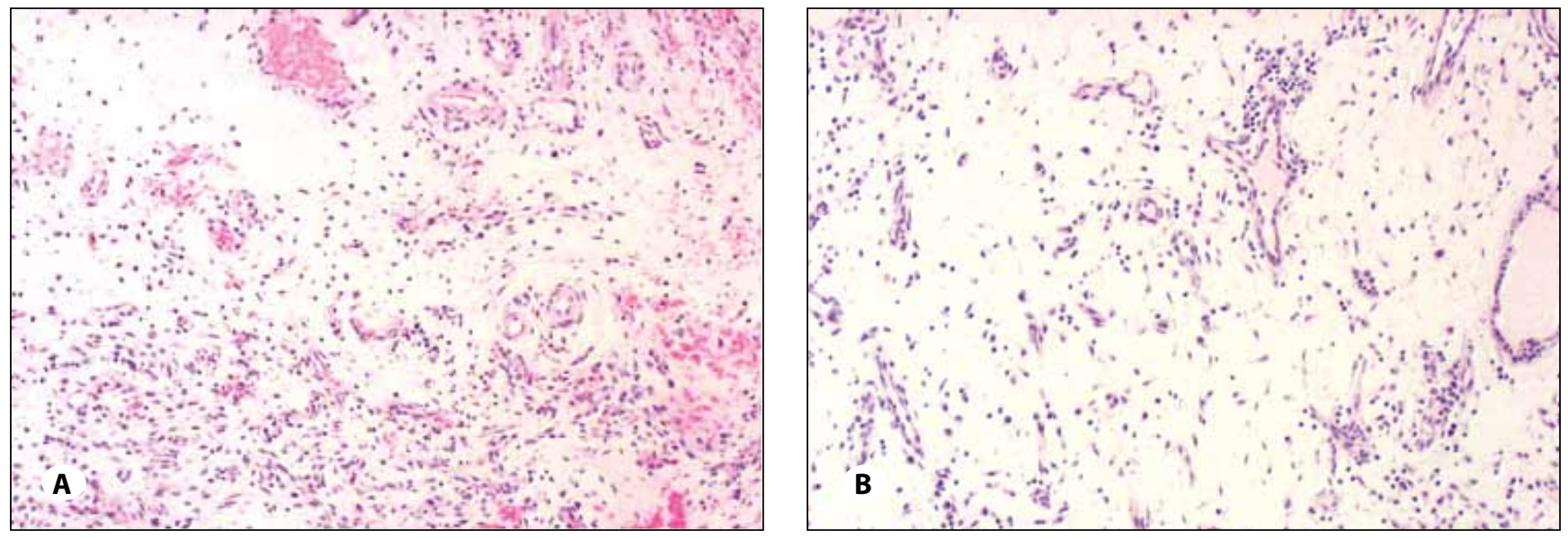

Figure 5: H\&E stained section (10x magnification) of sphenoid mucosa revealing moderate inflammation on A) Patient 1, B) Patient 2.
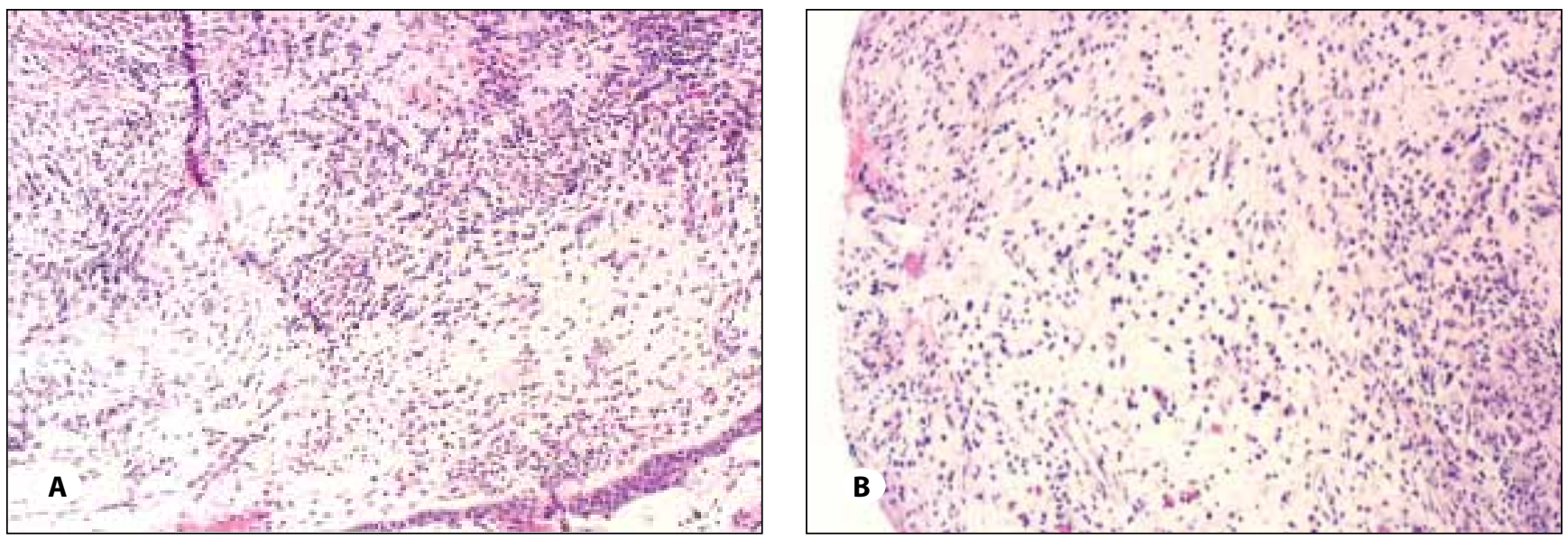

Figure 6: H\&E stained section (10x magnification) of sphenoid mucosa revealing moderate inflammation on A) Patient with electively removed pituitary adenoma B) Patient with lymphocytic hypophysitis. 


\section{CONCLUSION}

There is a temporal association with the radiographic finding of sphenoid sinus mucosal thickening and pituitary apoplexy. Sphenoid sinus mucosal thickening may be precedent and suggestive of an apoplectic event. Accordingly, the radiographic presence of sphenoid mucosal thickening may warrant early surgical intervention.

\section{REFERENCES}

1. Arita K, Kurisu K, Tominaga A, Sugiyama K, lkawa F, Yoshioka $H$, Sumida M, Kanou Y, Yajin K, Ogawa R: Thickening of sphenoid sinus mucosa during the acute stage of pituitary apoplexy. J Neurosurg 95:897-901, 2001

2. Liu JK, Couldwell WT: Pituitary apoplexy: Diagnosis and management. Contemp Neurosurg 25:1-6, 2003

3. Liu JK, Couldwell WT: Pituitary apoplexy in the magnetic resonance imaging era: Clinical significance of sphenoid sinus mucosal thickening. J Neurosurg 104:892-898, 2006

4. Semple PL, Webb MK, de Villiers JC, Laws ER Jr: Pituitary apoplexy. Neurosurgery 5:65-73, 2005

5. Thapar K, Laws ER: Pituitary tumors: Functioning and nonfunctioning, in Winn RH (ed): Youmans Neurological Surgery. Philadelphia: Elsevier Inc., 2004:1202-1203 